\title{
EPIDEMIA DE TUNGÍASE NO RIO GRANDE DO SUL
}

\section{Ricardo Soares Matias}

\author{
Oautor relata as primeiras informações epidemiológicas sobre surtos de tungiase \\ (Tunga penetrans) no Rio Grande do Sul.
}

Palavras-chaves: Tunga penetrans. Tungiase.

A tungiase é uma ectoparasitose causada pela Tunga penetrans (Linné, 1958), Jarocki 1838; Sarcopsylla penetrans Westwood 1840; Pulex penetrans Linné 1758; Rynchoprion penetrans Oken 1815; Dermatophilus penetrans (Lucas 1839) GuérinMeneville $1843^{4} 616$.

Embora as pulgas humanas, do cão, do gato e dos ratos sejam bem conhecidas pela sua importância em saúde pública, outras, que apresentam hábitos mais parasiticos, continuam confusas na literatura e seus hábitos erroneamente descritos. Esta pulga vulgarmente chamada sand flea, chigoe, chigger, jigger, nigua, chique, djigga, pico, jique, chica, suthipique, bicho-do-pé, bicho-do-porco, jatecuba, etc., é cientificamente chamada de Tunga penetrans 2467.

Esta parasitose é causada pela fêmea fecundada que penetrando no hospedeiro exerce o hematofagismo a fim de dar continuidade ao seu ciclo vital. $O$ macho, apesar de ser hematófago, não se fixa no hospedeiro, libertando-se assim que termina o repasto, da mesma forma que a fêmea não fecundal1 17 .

Seu tamanho é cerca da metade da pulga humana, Pulex irritans, diferenciando-se desta por apresentär a fronte angulosa e as mandibulas largas, longas e fortemente serrilhadas, apresenta seus três segmentos torácicos muito curtos. Habitam locais arenosos, secos, perto de habitações humanas, estábulos, chiqueiros e cabanas 4671819 .

Alimentam-se de sangue dos animais de sangue quente como cães, gatos, ratos e outros inclusive animais selvagens, sendo especialmente atraidas pelos porcos e homens. Em seu ciclo de vida, a Tunga penetrans é mais parasita que todas as outras pulgas. A maioria delas se alimenta intermitentemente do hospedeiro, vivendo em associação fechada, mas não

Divisão de Zoonoses Vetores da Secretaria da Saúde e Meio Ambiente do Rio Grande do Sul.

Endereço para correspondencia: Dr. Ricardo Soares Matias. Rua Vigario Jose Inacio 303. 3: andar

90020 Porto Alegre, RS.

Recebido para publicação em 18/07/86. no hospedeiro. As pulgas humanas vivem nas roupas, pêlos e tocas. A Tunga penetrans precisa de seu hospedeiro para que haja continuidade de seu ci$\mathrm{clo}^{3} 41371819$.

Sua penetração dura de 5 a 10 minutos e após 5 a 10 dias está apta a eliminar de 100 a 200 ovos 4567891011171819 , estes chegam à fase de larva de 3 a 8 dias, levando 15 dias até a forma de pupa e 7 dias à fase adulta, variando de 17 a 30 dias seu ciclo evolutivo 45.68101120 .

São poucos e antigos os relatos de surtos de tungíase, além de muito pobres em informações epidemiológicas. Os primeiros registros históricos devem-se a Gonzalo F. de Oviedo e Valdes (1526), o qual relata que a tungiase ficou conhecida dos espanhóis quanto Cristóvão Colombo aportou em Guadahani, a 12 de outubro de 1492, descrevendo a doença que os espanhóis sofreram quando partiram do Haiti em janeiro de 1493111317.

Em 1538 Gonzalo Ximenez de Quesada conduziu uma expedição militar até Sorotoca, Bogotá, abandonada por um surto de bicho-do-pé, atacando violentamente os soldados 17 .

Segundo Guyon (1870) tropas francesas tiveram experiência semelhante à de Quesada em Perote (1862). Em 1863 tropas francesas tiveram o mesmo problema em Orizaba na América do Sul. Buttikofer (1890) em sua visita à Monrovia, capital da Libéria, relata a alta infestação desta cidade pela Tunga penetrans, ocasionando danos às pessoas, inclusive com perdas de dedos dos pés 1317 .

Jolly ${ }^{14}$ relata como em 1915 sua tropa sofreu terrivelmente com esta praga no leste da África. Em poucas semanas a metade da tropa estava incapacitada para a marcha. Hoepli (1963) descreve o sofrimento da tripulação do navio Thomas Mitchell (1872) especialmente pelo fato de desconhecerem a causa 1213 .

Decle (1898) refere que no Forte Raymond de 160 soldados e 70 carregadores, 72 soldados e 30 carregadores ficaram incapacitados para o serviço em virtude de úlceras causadas por esta pulga e 30 homens ficaram aleijados. No Forte Grant a proporção de 
inválidos por esta pulga chegou a mais de $50 \%$. Alguns tinham os ossos do polegar dos pés expostos 10 .

Além destes, outros autores como Thevet (1558), Renger (1832/1835), Winterboton (1803), Adamson (1759), Bajon (1734) relatam casos de tungíase 1317 .

Richard Schomburgk viajando no interior da Guiana Britânica, em 1840, descreve o que encontrou na aldeia de Warrau: "....além dos adultos, crianças principalmente, apresentavam os pés, nádegas, cobertos de feridas e algumas extremidades deformadas pela Tunga penetrans. $\mathrm{O}$ autor refere ter experimentado uma reação dolorosa e pruriginosa nos pés, de onde um nativo retirou 83 parasitas em poucos minutos. Seguiuse uma marcada inflamação. No local da coceira há um aumento de volume do parasita causando dor. Fica uma área eritematosa com um ponto preto no centro, que são os segmentos posteriores, onde se localizam o ânus por onde os ovos são liberados e o estigma respiratório". Estas caracteristicas são relatadas por vários autores ${ }^{134671819}$.

Os locais mais afetados são a região plantar, dedos e sob as unhas dos pés. Quando são muitas e próximas uma da outras na borda do calcanhar recebe a denominação de "favo de mel"1 678131819.

Com a retirada dos parasitas, a ferida pode se contaminar causando tétano, gangrena 134671819 , auto-amputação 21113 , necrose óssea e tendinosa ${ }^{11}$, etc.

As informações existentes sobre surtos de tungiase são raras. Quando muito, sabemos informalmente de um ou outro caso, principalmente de surtos urbanos. Mais como curiosidade do que uma constatação científica. $\mathrm{Na}$ realidade pouco ou nada se discutiu sobre esse problema. Aliam-se a isto as informações existentes: antigas e carentes de detalhes.

Razões mais do que suficientes para encararmos com certo ceticismo informações que nosso Serviço de Controle de Vetores começou a receber em abril de 1982 sobre surtos de Tunga penetrans em dois municípios do Rio Grande do Sul: Gravatai e Rio Grande. Fazia-se necessária uma avaliação para melhor caracterizarmos o problema.

\section{MATERIAL E MÉTODOS}

A utilização de um Inquérito Epidemiológico Domiciliar nos pareceu adequada na investigação. Além disso, teríamos que coletar amostras de solo para serem realizadas análises fisico-químicas com a intenção de avaliarmos alguns parâmetros como textura e outros itens que pudessem aumentar o contingente de informações sobre sua ecologia.

\section{RESULTADOS}

\section{a. O surto em Rio Grande}

Em abril de 1982, fomos a Rio Grande investigar as principais áreas infestadas: vilas Profilurb I e II e Santa Rosa. Em alguns casos a infestação era tal que as pessoas não podiam andar; se locomovendo no colo ou de joelhos. Haviam pessoas com os dedos dos pés mutilados, vários casos de infecção, perdas de extremidades, várias regiões do corpo infestadas, o interior das residências infestadas, inclusive nos berços. $O$ sofrimento sentido pela população era visivel. O Posto Avançado de Saude, a Unidade Sanitária e os hospitais năo estavam fazendo registros dos casos e com isto perdemos informações valiosas. Na Santa Casa os médicos nos informaram de dois óbitos por tétano, causado pelo bicho-do-pé, além de casos de amputação.

Sugerimos algumas medidas: 1) cadastramento de todos os casos; 2) vacinação antitetânica; 3) orientação da população através dos meios de comunicação quanto aos cuidados a serem tomados e a procurar um posto de saúde; 4) solicitação às professoras de como orientar os alunos e pais e como retirar o parasita com assepsia; 5) pulverização do solo com Malathion a $0,5 \%$, segundo orientação da Fundação Estadual de Engenharia do Meio Ambiente (FEEMA) do Rio de Janeiro, usando equipamento do Corpo de Bombeiros, mangueira com terminal em chuveiro. Neste mesmo momento suspendemos esta aplicação com receio de intoxicação e contaminação do lençol d'água, que é superficial, até que testássemos um novo produto.

Retornando em agosto de 1982 verificamos que haviam feito o levantamento só até julho, a vacinação não se tornou rotina, apenas algumas professoras deram as orientações, o Posto de Saúde continuava negando-se a atender muitos dos casos.

Passamos então a realizar um inquérito epidemiológico. A idéia era aplicarmos o inquerito em $50 \%$ das residências. Como haviam muitas fechadas, o percentual foi menor como mostra a Tabela 1. Os Profilurb I e II são áreas de assentamento espontâneo, pois o programa oficial de assentamento não funcionou. Não há luz, água encanada, esgoto, coleta de lixo, as ruas não são calçadas, as casas são construídas com restos de material de construção ou outro e sem piso. Há uma escola, um posto avançado de saúde e pequeno comércio local. O Profilurb I tem ao redor 14,85 ha com 317 residências e o Profilurb II tem ao redor de 14,95 ha com 200 residências.

A vila Santa Rosa tem 56,73 ha com 480 residências, sendo poucas as de alvenaria. Algumas são construídas em terreno adquirido legalmente, mas as condições de infra-estrutura são as mesmas das áreas anteriormente descritas.

Estas três áreas eram anteriormente usadas para criação de animais, principalmente suínos sem 
Matias RS. Epidemia de tungiase no Rio Grande do Sul. Revista da Sociedade Brasileira de Medicina Tropical 22: 137-142, Jul-Set, 1989

Tabela 1 - Caracterização de surto de tungiase em Rio Grande e Gravataí (RS).

\begin{tabular}{lcccc}
\hline & Santa Rosa & Profilurb I & Profilurb II & Morada do Vale II \\
\cline { 1 - 4 } No de residências existentes & 480,00 & 317,00 & 200,00 & 3886,00 \\
N. de residências visitadas & 104,00 & 115,00 & 58,00 & 448,00 \\
Percentual de cobertura & 21,66 & 36,27 & 29,00 & 11,53 \\
Percentual de residências infestadas & 88,46 & 95,65 & 87,93 & 56,69 \\
No de pessoas existentes & 446,00 & 558,00 & 231,00 & 1950,00 \\
Percentual de infestação & 82,62 & 81,36 & 71,29 & 39,94 \\
\hline
\end{tabular}

Tabela 2 - Distribuição etária de infestados por Tunga penetrans em Rio Grande e Gravataí.

\begin{tabular}{ccccc}
\hline Faixa etária & Santa Rosa & Profilurb I & Profilurb II & Morada do Vale II \\
\hline$<1$ & 4 & 2 & 2 & 5 \\
$1-4$ & 36 & 38 & 18 & 92 \\
$5-9$ & 48 & 61 & 22 & 127 \\
$10-14$ & 50 & 66 & 23 & 62 \\
$15-19$ & 36 & 45 & 17 & 74 \\
$20-24$ & 45 & 54 & 14 & 58 \\
$25-29$ & 32 & 35 & 13 & 99 \\
$30-34$ & 25 & 43 & 7 & 78 \\
$35-39$ & 13 & 36 & 8 & 57 \\
$40-44$ & 25 & 14 & 12 & 35 \\
$45-49$ & 19 & 16 & 6 & 27 \\
$50-54$ & 67 & 16 & 12 & 20 \\
$>54$ & 26 & & & 45 \\
\hline
\end{tabular}

qualquer cuidado higiênico, permanecendo ainda hoje algumas criações.

\section{b. O surto em Gravataí}

Neste local, em abril de 1982, aplicamos o questionário em $10 \%$ das residências, cujos resultados se encontram nas Tabelas 1 e 2. Em cada 10a residência, a partir da esquina para a direita, o questionário era aplicado. Caso a residência estivesse fechada, passariamos imediatamente à seguinte.

Esta vila é formada de 123 quadras urbanizadas: 4 escolas, posto de saúde, consultório médico e odontológico particulares, armazéns, açougues, supermercados, coleta regular de lixo, água encanada, luz, esgoto, ruas calçadas e linhas regulares de ônibus. As residências, em número de 3886 são de madeira ou de alvenaria, vendidas pelo BNH. Para a construção das residências a firma revolveu todo o terreno e o nivelou. Cada uma das casas tem uma área ao redor de $300 \mathrm{~m}^{2}$ onde, nos jardins de todas elas, foram colocadas leivas de grama, ou seja, quadrados com a grama já plantada que colocada sobre o solo não sofre influência deste. Estas leivas são provenientes de diferentes locais.

A região era, anteriormente, da Sociedade Beneficente Portuguesa, a qual tinha uma plantação de eucaliptos e alguns animais criados em sistema de confinamento (suínos e bovinos de leite) em boas condições sanitárias.

Apesar do percentual de infestação ser alto, não observamos casos de infecção secundária. O problema residia na infestação, mas com posterior enucleação do parasita pelas próprias pessoas ou no Posto Médico. Além disto, as pessoas preocupavam-se em tomar cuidados gerais, tais como usar calçado, limpar o terreno e outros e ainda pressionavam a Secretaria de Saúde a resolver o problema.

\section{DISCUSSÃO}

A região tropical, por suas características climáticas, desenvolve, em conseqüência, uma exuberante flora e fauna, as quais permitem a formação de numerosos nichos ecológicos naturais e em consequaência o desenvolvimento de vários patógenos.

A introdução do homem nesses nichos desenvolve a formação de vários complexos patológicos de Sorre ${ }^{20}$. Esses nichos ecológicos e complexos patológicos ocorrem tanto em ambientes naturais como urbanos. 
Tal fato por nós foi observado em Rio Grande nas Vilas Profilurb I e II e na Santa Rosa e em Gravataí na Cohab-C e Morro do Coco. Como não sabemos se a introdução inicial foi feita pelo homem ou animal, consideremos a situação em que não havia ainda um assentamento humano. Anterior à ocupação, estas áreas eram usadas para a criação de animais extensivamente e sem cuidados higiênicos, vivendo ai enzooticamente, uma vez que sua capacidade de dispersão é pequena. Precisando, para dispersar-se de veiculos e/ou portadores. A introdução do homem, com os assentamentos, possibilitou sua maior dispersão e abundância, constituindo complexos patogennicos e o problema instala-se.

A tungíase é realmente um problema tropical, uma vez que sua distribuição, segundo vários autores, se restringe às regiões tropicais e subtropicais do continente americano entre as latitudes de $30^{\circ} \mathrm{N}$ e $30^{\circ} \mathrm{S}$, Índias Ocidentais e África 346817 .

Considerando que já faz cinco séculos que se conhece a tungiase, é de estranhar-se o pouco ou nenhum interesse que a Saúde Pública tem dado ao problema, principalmente, em se conhecendo os danos causados: mutilações e óbitos. abaixo:

Pelo que foi exposto, ficam claras as conclusões

1. A tungiase é uma enfermidade de graves conseqüências, multiladora, podendo ser fatal e de importante agravo social;

2. As informações sobre surtos, tratamento humano, controle ambiental, biologia, ecologia e profilaxia são inexistentes e quando surgem são pobres em detalhes;

3. Dentre as medidas preventivas, ainda é válido o uso de calçados, apesar de não proteger totalmente. Algumas pessoas relataram que mesmo estando calçadas retiraram parasitas de seus pés. Nós mesmos quando estávamos fazendo coleta de material em Rio Grande, mesmo estando de botas, fomos atingidos nos pés;

4. Quanto à limpeza da área, está bem claro não ter relação absolutamente alguma com a maior ou menor contaminação ambiental, como verificamos pelos níveis de infestação nas áreas avaliadas. Mas é um importante fator na determinação de infecções secundárias. Isto está visível ao verificarmos a baixa incidência de infecções na Morada do Vale II e um grande número de problemas em Rio Grande: presença do característico "favo de mel" nos pés, grande quantidade de parasitas em diferentes partes do corpo (pernas, braços, mãos, costas, barrigas, etc), grande número de pessoas sem extrair os parasitas pelas infecções existentes, sendo dolorosa sua retirada, algumas pessoas tendo que se submeter a anestesia geral (principalmente crianças) para poder extrair os parasitas, feridas infectadas, sofrimento, dificuldade de andar, obrigando-as a deslocar-se de joelhos ou no colo, perdas de extremidades etc.

5. A sintomatologia observada é a mesma descrita pelos autores: inicialmente pequeno prurido e dor que aumenta com o aumento do abdômen do parasita determinado pelo desenvolvimento dos ovos, eritema e um pequeno ponto negro no centro determinado pela presença de ânus e forma respiratória;

6. Os locais åfetados são os mais variados, principalmente nas crianças por exporem mais partes do corpo ao solo: pés, pernas, braços, costas, nádegas, mãos, rosto e barriga são alguns dos locais afetados;

7. Nāo existe uma única explicação para o surto, mas diferentes razões para diferentes locais. Na Morada do Vale II, por exemplo, não há história de presença de animais criados em condições que pudessem estar mantendo enzooticamente o parasita. Além disto, todo o terreno foi revolvido e nivelado. O que há de comum é o fato de todas as residências terem recebido leivas de grama provenientes de vários locais. Essas tem o solo arenoso e com bastante matéria orgânica. Vários moradores relatam a presença dessa pulga na grama nos jardins, que não é o habitat normal desse organismo. Estes fatos nos levam a crer que essas leivas tenham sido os veículos introdutores do parasita nessa área.

$\mathrm{Na}$ medida em que as pessoas vieram ocupar a área aumentou a oferta de alimento para a Tunga penetrans. Além disto animais como os cães passaram a ser, também, parasitados. Somando-se o movimento das pessoas e animais - migração interna - a não retirada desses parasitas dos cães, principalmente, o parasita teve condições de aumentar sua distribuição e conseqüente abundância, que aumentando a possibilidade de novas infestações fecha o ciclo.

No caso de Rio Grande as três áreas eram anteriormente usadas para a criação de suinos sem qualquer cuidado higiênico. Segundo moradores das redondezas estes animais tinham o bicho-do-pé. Nesta situação as pulgas mantinham-se numa situação enzoótica. $\mathrm{Na}$ medida em que as pessoas passaram a ocupar a área o processo passou a ser o mesmo da situação anterior.

O movimento de pessoas e cães infestados e veículos como areia, leivas de grama, madeiras para a construção das casas provenientes de locais conta- 
minados favorecem a dispersão do parasita. A partir do momento em que o susceptivel torna-se infestado, o processo continua-se em cadeia, ainda mais que a Tunga penetrans não apresenta mecanismos naturais de controle, exceto o próprio clima e mais especificamente a chuva e assim mesmo, momentaneamente. $\mathrm{Na}$ presença de grande quantidade de alimento e espaço, seu crescimento se vê favorecido a aumentar exponencialmente não ultrapassando nunca a capacidade de porte porque esta é ilimitada, mas perde seu controle homeostático caracterizando-se como uma praga. Seu crescimento será interrompido nos momentos de chuva, retornando a crescer após seu término;

8. Apesar de ser uma parasitose cujas atividades se exacerbam durante o verão, houve casos de ataque nos períodos de inverno e mesmo chuvosos. Supomos que nos meses frios o parasita fique em estado de redução metabólica enterrado na areia, retornando à atividade com grande voracidade quando molestadas. Tal ocorre, como verificamos por várias vezes, ao revolverem a terra, fazer canteiros ou quando estão reformando residências ou construindo-as. Nestes momentos, as pessoas são obrigadas a interromper o serviço em virtude do ataque;

9. Apesar da literatura citar como habitat solos secos e arenosos 4671819 não foi o que observamos. Em Rio Grande coletamos, de forma aleatória, 12 amostras de solo nas ruas e peridomicílios. Tivemos $100 \%$ de solo arenoso. Em Gravatai sorteamos 3 quadras sem infestação, 6 com $50 \%$ ou mais de pessoas e residências infestadas e 5 com $50 \%$ ou menos de pessoas e residências infestadas. Das quadras sem infestação, 2 amostras eram de solo franco argilo-arenoso e 1 franco-arenoso; das quadras com $50 \%$ ou mais de infestação 3 tinham solo franco argilo-arenoso, 2 franco-arenoso e 1 argiloso; das quadras com $50 \%$ ou menos de infestação 2 tinham solo franco argilo-arenoso e 3 franco-arenoso;

10. É medida importante recolher cães vadios, orientar a população quanto aos cuidados que se deve ter quando da enucleação do parasita e realizar vacinação antitetânica, pois é possível o tétano veiculado pela própria Tunga penetrans ${ }^{9}$ ou através de instrumentos;

11. Devem ser desenvolvidas normas sobre ocupação de áreas para assentamentos, não os permitindo em áreas de criação de animais ou com história de tungiase. Caso seja necessário a área deverá sofrer tratamento químico anterior ao assentamento. Atualmente estamos usando o piretróide K-Othrine C.E. $0,25 \%$ (deltametrina) em solução a $0,6 \%$; veículos como leivas de grama, areia, madeiras e outros, provenientes de áreas infestadas também devem sofrer tratamento prévio antes de serem introduzidos em novas localidades ou não introduzi-los;

12. Devem ser desenvolvidos estudos quanto a um maior conhecimento da ecologia da Tunga penetrans, bem como novas metodologias de controle, principalmente no uso de produtos químicos, observando-se cuidados de eficácia, impacto ambiental e toxicidade, além de medidas profiláticas e processos de avaliação adaptáveis a cada área geográfica;

13. A tungiase, em nosso estado, é atualmente, um grave problema de saúde pública e, como tal, deve ser encarada pelas autoridades sanitárias;

14. Pelo fato de ser uma enfermidade de rápida distribuição e de dificil controle, deve ser caracterizada como de notificação obrigatória, a fim de que os focos sejam imediatamente controlados, evitando-se surtos.

\section{SUMMARY}

The author relates epidemiological information about an outbreak of tungiasis (Tunga penetrans) in Rio Grande do Sul.

\section{Key-words: Tunga penetrans. Tungiasis.}

\section{REFERÊNCIAS BIBLIOGRÁFICAS}

1. Bell A, Neely CL, Peeples J. Tungiasis in Tennessee. Southern Medical Journal 72: 141-143, 1979.

2. Blanchard R. Présence de la chique (Sarcopsylla penetrans) à Madagascar. Archives of Parasitology 2: 627630, 1899.

3. Brothers W. Tungiasis (Tunga penetrans) in Utah. Journal of Parasitology 65: 782, 1979.

4. Bruce CO, Kinigin TD, Yolles SF. Discussion of chigoe (Tunga penetrans) based on experiences in British Guiana. Military Surgeon 91: 446-456, 1942.

5. Cooper JE. An outbreak of Tunga penetrans in a pig herd. Veterinary Record 80: 365-366, 1967.

6. Coutinho E. Tungiase. In: Tratado de Clinica das Doenças Infectuosas, Parasitárias e Peçonhentas. Rio de Janeiro, Guanabara Koogan p. 686-689, 1957.

7. Darling AN. Anotaçōes sobre as Espécies mais Importantes. Apud Pessoa SB (ed.). Parasitologia Médica. Guanabara Koogan, Rio de Janeiro, p. 786-804, 1976.

8. Faust EC, Maxwell TA. Finding of larvae of chigo, Tunga penetrans, in scrapings from human skin; report of case. Archives of Dermatology and Syphilology 22: 94 97, 1930

9. Floch $\mathrm{H}$. Tétanos post-quinique et vaccination antitétanique. Bulletin of the Academy of Medicine 133: 419 $423,1949$. 
10. Goldman L. Tungiasis in travelers from tropical Africa. Journal of the American Medical Association 236: 1386, 1976.

11. Gordon TM. Jigger flea. The Lancet 2: 47-49, 1941.

12. Henning G. Zur geschichte des sandflohes (Sarcopsylla penetrans L.) in Afrika Naturwiss Worchencrifts 19 310-312, 1904.

13. Hoepli R. Early references as to the occurrence of Tunga penetrans in tropical Africa. Acta Tropica 20: 143-153, 1963.

14. Jolly GG. An entomological episode of the East African campaign. Indian Medical Gazette 61: 164-165, 1926.

15. Lacaz CS, Baruzzi RG, Siqueira Junior W. Introdução à Geografia Médica do Brasil. Edgard Blucher, Ed. da
Universidade de São Paulo, 1972.

16. Lewis RE. Notes on the geographical distribution and host preferences in the order Siphonaptera. 1. Pulicidae. Joumal of Medical Entomology 9: 511-520, 1972.

17. Reiss F. Tungiasis in New York City. Archives of Dermatology 93: 404-407, 1965.

18. Rey L. Sifonápteros: as pulgas e a peste. Parasitologia. Guanabara Koogan, Rio de Janeiro, p. 615-627, 1973.

19. Sampaio SAP. Dermatoses produzidas por ácaros. In: Veronesi R (ed.). Doenças infecciosas e parasitárias. Guanabara Koogan, Rio de Janeiro, p. 963-968, 1976.

20. Sorre M. Fundamentos biológicos de la geografia humana. Ensayo de uma ecologia del hombre. Ed. Juventud, Barcelona, 1955. 